\title{
La mundialización de la cuestión laboral y el comercio. Respuestas de articulación de los nuevos regionalismos en América del Norte, Europa y el Cono Sur de América Latina ${ }^{1}$
}

\section{Lincoln Bizzozero}

En definitiva, si nos atenemos a las modificaciones estructurales que esta experimentando el sistema internacional, las respuestas planteadas desde el Tratado de Libre Comercio de América del Norte, de la Unión Europea y el MERCOSUR frente a la inclusión de la cláusula social en el régimen de comercio internacional, muestran direcciones estratégicas diferentes, lo cual dificultará notoriamente una aproximación occidental en la primera década del próximo milenio, al menos en lo que concierne la definición de este tema.

\section{Introducción}

La cuestión laboral entendida en un sentido amplio -derechos de los trabajadores, protección de determinados grupos, condiciones de trabajo, parámetros básicos de remuneración, seguridad social y en el empleo y políticas contra el desempleo- ha pasado a formar parte de los temas de la agenda de las instituciones internacionales, de los foros y órganos correspondientes en las regiones y procesos de integración, y también de los gobiernos en el nivel nacional. La relación entre estos tres niveles -el nacional, regional y mundial- no resulta siempre evidente, pero las interacciones existentes en el contexto de una creciente internacionalización están pautando y condicionando el mercado laboral.

\footnotetext{
: Este documento que fue elaborado con la colaboración de Ana Pastorino, constituye uno de los productos del Proyecto "Regulación y flexibilidad en el mercado de trabajo: el marco intemacional y el regiona", financiado por la Comisión Sectorial de Investigación Científica (CSIC) de la Universidad de la República Oriental del Unuguay.
} 
$\mathrm{Si}$ bien los factores y variables que inciden en los tres niveles son diversos, los elementos que han desencadenado la inclusión del tema en las diferentes agendas son: la introducción del "costo laboral" y su relación con los otros indicadores de competitividad con sus posibles consecuencias en la presentación del "mercado laboral" al inversor extranjero y en las adaptaciones (y transformaciones) que puedan derivar de las relaciones laborales; ${ }^{2}$ y la internacionalización de ese costo en el producto a exportar con las lógicas consecuencias que tienen los principios adoptados en la fijación del precio, en la conformación de un mercado laboral internacional y como resultado en el incremento del desempleo. ${ }^{3}$ Esta última aproximación lleva a que se plantee en el debate la necesidad y posibilidad de incluir un piso elemental de derechos laborales esenciales como base del comercio internacional, para partir de condiciones de equidad en el mercado y para que los criterios de competencia no sean distorsionados.

En definitiva la cuestión laboral en sus diversas manifestaciones ha pasado a conformar uno de los aspectos sustantivos de la cuestión social, tanto como indicador de competitividad, que como exteriorización del componente "derechos laborales" en el producto a comercializar en el exterior. ${ }^{4}$ En estas distintas aproximaciones al tema, diversas instituciones internacionales se han hecho cargo de exponer su enfoque, ya sea partiendo de los "derechos del trabajador" como modelo de reflexión predominante, de los "derechos ciudadanos" o bien enfatizando la equidad y las ganancias colectivas. ${ }^{5}$

Por otra parte, las definiciones que han tenido los procesos de integración regional concerniente a los énfasis en la inserción competitiva, los objetivos

\footnotetext{
2 Sobre la estructura y funcionamiento de las relaciones laborales y sobre los distintos modelos nacionales y los posibles cambios nos remitimos a la selección de lecturas que hace Oscar Ermida Uriarte en el libro Curso Introductorio de Relaciones Laborales, Fundación de Cultura Universitaria, Montevideo, 1996. 3 El tema del empleo abarca más aspectos de lo que podria surgir del vínculo con el comercio, como surge del incremento del desempleo estructural y sus consecuencias en el piso desde el cual se parte en las políticas de empleo. Lo que considera esta reftexión es el desempleo ocasionado por la nueva división internacional del trabajo. En los paises de la OCDE, la apertura afectó sectores que requieren un uso intensivo de mano de obra. De acuerdo a estudios realizados, el número de desocupados pasó entre 1970 y 1995 de 8 a 35 millones de personas. Véase OCDE Estudio de la OCDE sobre el empleo. Mundi-Prensa Libros, España 1995.

4 Estas manifestaciones no son las únicas, pero son las más relevantes y sensibles al abordar el tema, sobre todo por el hecho de que se vincula con el tema del empleo. Otras perspectivas de la cuestión laboral que se han manifestado en el sector servicios y en las sociedades desarrolladas en general son: un mejor equilibrio entre el tiempo libre y el laboral; la disponibilidad global de más opciones personales para el empleado; y una mayor libertad y desapego del empleado con relación al puesto de trabajo, la empresa y su destino particular. Véase al respecto, Asociaciôn Europea de Direcciôn de Personal Flexibilidad en el trabajo. Estrategias y prácticas en Europa. Cómo organizar el trabajo de forma flexible. Ediciones Gestión 2000 S.A. Madrid, 1995.
} 
a los cuales apuntan y otorgan prioridad, las respuestas que plantean a la ecuación regionalismo-internacionalización, han llevado a incluir la cuestión laboral entre las mismas. En ese sentido, el Tratado de Libre Comercio de América del Norte (TLCAN), como la Unión Europea, por nombrar dos de los procesos que inciden en el sistema internacional tanto en materia de comercio de bienes y servicios, como de flujos de capital, han planteado aproximaciones al tema desde perspectivas diferenciadas. En el caso del Tratado de Libre Comercio de América del Norte, la inclusión de la cuestión laboral en un Acuerdo Paralelo, tiene como objetivo supervisar la aplicación de las normativas nacionales en las relaciones laborales (contrato y condiciones). Por otra parte, en la Unión Europea, el Tratado de Amsterdam de 1997, incluyó el tema del empleo y la política social comunitaria como componentes de la Europa social, profundizando un debate, que de por sí manifiesta divergencias y manifestaciones diferenciadas sobre prioridades e instrumentos.

Estas diferentes aproximaciones del Tratado de Libre Comercio de América del Norte y de la Unión Europea sobre el tema laboral surgen con posterioridad a que la Ronda Uruguay del GATT incluyera en la discusión la Cláusula Social, dejando abierta la posibilidad de que en determinadas circunstancias un país pueda ser objeto de sanciones en el marco del régimen de comercio internacional, siempre que no cumpla con los convenios internacionales de protección de los trabajadores o con las propias leyes laborales.

El punto de partida del trabajo es que estas manifestaciones sobre la cuestión social constituyen síntomas de una modificación más profunda, que atañe a las condiciones en que se piensa la convivencia de las comunidades humanas (local, nacional, regional, internacional y mundial), en sus diversos planos (económicos, ecológicos, institucionales, normativos, políticos y de toma y aplicación de decisiones). Esta modificación de los cimientos en la convivencia de las comunidades humanas condiciona las pautas en que se estructuran las diferentes respuestas estratégicas (el qué hacer, los instrumen-

\footnotetext{
5 Estas disyuntivas tambiēn se encuentran presentes en los mismos movimientos sociales y de trabajadores, pautando las dificultades en ubicar objetivos y consignas abarcadoras. En ese sentido, resulta ilus. trativo esta afirmación realizada en una publicación del Instituto de Formación Subregional de la Central Latinoamericana de Trabajadores "...la Central estima que el tema empleo/desempleo desafía por igual al Movimiento de los Trabajadores, ya que los modelos sindicales imperantes, en general, tienden a defender a los que tienen trabajo y no sabe qué hacer con los que no lo tienen o malviven en la economía informal..." Presentación del libro de Héctor Roberto Roudil Empleo y desempleo en los países del Mercosur y Chile. Ediciones INCASUR, Buenos Aires, 1995.
} 
tos y las prioridades como Estado y en tanto opción regional, la definición de las modalidades de participación de la sociedad civil en la respuesta, y las nuevas bases contractuales entre la esfera pública y la privada) y las dis-tintas percepciones sobre los principios y valores básicos (mayor cooperación o conflicto de acuerdo a las pautas de convergencia o divergencia en las definiciones; posibilidades de aproximación por identidades culturales o de "civilización".

Estos tres planos -estructural, de respuesta estratégica y de definición de valores y pautas comunes- señalan las tensiones en que se manejan en el presente las distintas comunidades humanas, que afectan las diversas dimensiones de la interacción entre los hombres y las sociedades. Entre ellas la cuestión laboral ha pasado a ser uno de los temas donde se manifiestan con mayor sensibilidad los cambios estructurales a los que hacíamos referencia, por diversos motivos. En primer lugar, porque atañe en particular a una lógica de funcionamiento de la sociedad construida sobre la modernidad, y la aceptación del cambio implica modificar determinadas bases sobre las cuales se edificó la visión de la sociedad y del mundo en varias generaciones. En segundo término, porque esos cambios atraviesan los distintos sectores y generaciones de la sociedad, planteando de esa manera la necesidad de respuestas negociadas en nuevos contextos, que todavía no se encuentran suficientemente exploradas y estructuradas, ya que se continúa con perspectivas sectoriales y corporativas provenientes de la "modernidad". En tercer lugar, porque las lógicas del entomo se han modificado, tanto en su dimensión ambiental, institucional, internacional, como también humana, en cuanto el hombre en su especificidad e individualidad ha pasado a ser el demandante y el beneficiario de los productos ofrecidos. ${ }^{6}$ Finalmente, porque esos cambios provocan lógicas repercusiones en los sistemas políticos, los cuales se ven obligados a otorgar respuestas de diverso signo, enfrentados a la tensión derivada de las funciones de representatividad y mediación con la sociedad, las condiciones estructurales a las que se ven enfrentados y que deben asimilar y las opciones y respuestas estratégicas que se plantean desde el gobierno que deben debatir, convalidar y articular con la sociedad.

\footnotetext{
${ }^{6}$ Por supuesto que no entran en esta consideración las modalidades en que los medios de comunicación han definido su posición en el mercado para aprovechar esta nueva situación, tanto en su faz subjetiva -incidencia en las opciones del sujeto-consumidor, como en la objetiva- nuevas manifestaciones de la tecnología, entre los cuales ubicamos el marketing internáutico, el virtual, entre otros. Lo que enfatizamos es el reconocimiento de la especificidad de la persona en su individualidad, en los criterios de adaptación empresarial al mercado.
} 
Este trabajo tiene por objetivo visualizar los planteos y respuestas que otorgan los procesos regionales de América del Norte, de Europa y del Cono Sur de América Latina frente a la inclusión de la dimensión social en el comercio internacional. ${ }^{7}$ Este tema abre varios temas complejos referidos a la posibilidad de que puedan concretarse determinados principios comunes en los organismos multilaterales sobre los vínculos entre la cuestión laboral y el comercio internacional; las definiciones de política exterior de Estados Unidos en la conexión de la democracia con la dimensión social; el papel de los nuevos regionalismos en el sistema internacional; la introducción de la sociedad civil y sus consecuencias en el control de los principios sociales y la viabilidad de que puedan definirse modelos regionales diferenciados frente a la interdependencia global. ${ }^{8}$

El trabajo comenzará por delimitar el objeto analítico: la incidencia de la cuestión laboral en el costo del producto y las consecuencias que genera en el comercio internacional. Por otra parte se plantean las dificultades en llegar a un equilibrio por parte del mercado debido, a las diferencias existentes entre los Estados en sus respuestas de adaptación en distintas dimensiones concernientes a este tema.

Este aspecto metodológico resulta fundamental, desde el momento que el tema abordado, en tanto problema específico de las agendas, participa de los tres niveles en que se plantean los debates y opciones atinentes al mismo: el nivel internacional, el regional y el nacional. De esta manera la cuestión laboral, como otras cuestiones derivadas de la mundialización nos pone delante de aspectos básicos vinculados con la interacción entre distintas comunidades humanas, en la medida que contiene códigos y pautas culturales diferentes vinculados con el funcionamiento de la sociedad y el papel del individuo.

En segundo lugar, el trabajo explora en la posibilidad de definir determinados principios básicos, a ser aplicables a través de la "cláusula social", o mediante una armonización mundial de normas laborales. Para ello se anali-

\footnotetext{
7 Las referencias institucionales de esos regionalismos son: el Tratado de Libre Comercio de América del Norte, la Unión Europea y el MERCOSUR. El espacio de libre comercio transatlántico propuesto por Estados Unidos no fue aprobado por la Uniön Europea y el Acuerdo de Libre Comercio de las Américas constituye una línea de desarrollo de la política exterior de Estados Unidos, que tiene efectos varios sin que todavia podamos hablar de un régimen internacional con efectos vinculantes para los Estados.

"La jdea de un "modelo" no está tomada en el sentido de visualizar una estructura definida, sino más bien como una construcción a partir de determinado ordenamiento institucional, lógicas de los actores y orientaciones de política. Véase al respecto, Mario Telo (dir) - Corinne Gobin (col) Quelle Union Sociale Européenne. Acquis institutionnel, acteurs et défis Institut d'Etudes Européennes, U.L.B., Bruselas, 1986.
} 
za en particular la opción tomada por Estados Unidos de apoyar la "cláusula social" para de esa forma otorgar un contenido democrático a la liberalización económica. En este trabajo se plantea que el debate en las instancias internacionales, en los cuales podría configurarse un régimen internacional del mercado laboral, muestra las dificultades en definir determinados principios nucleares que posibiliten avanzar en la concreción de normas y reglas en los diferentes marcos de relaciones laborales que afectan a la producción y al comercio. Por otra parte se señala que la opción democrática de política exterior adoptada por Estados Unidos, plantea una perspectiva que lleva a que la sociedad civil se encuentre representada y pueda al mismo tiempo ejercitar su derecho de "control" y "vigilancia" de la agenda social.

Como en las instancias internacionales no se ha podido avanzar lo suficiente en la definición de los contenidos de un régimen internacional de la cuestión laboral vinculada al comercio, se han dado respuestas y aproximaciones desde procesos regionales. En ese sentido, resulta pertinente preguntarse si los procesos de integración en tanto entidades regionales, tienen especificidad como tales en el ámbito internacional y no constituyen solamente una respuesta intermedia entre el nivel nacional y el internacional, lo cual diluiría todo acuerdo y opción regional.

Esta apertura analítica sobre los regionalismos es parte de un debate internacional sobre sus características y funciones en el sistema internacional. $\mathrm{La}$ interrogante implícita es si los regionalismos pueden ser considerados entidades intermedias en el sistema internacional, que definan nuevas aperturas representativas y sociales tanto entre diferentes regiones como entre distintas sociedades y etnias. En esta aproximación se da una respuesta positiva a esta interrogante, señalando además que la contestación que se otorgue a la cuestión social plantea respuestas diferenciadas en lo que concierne el modelo de desarrollo y condiciona por ende las posibilidades de una respuesta estratégica. ${ }^{9}$

Un último núcleo de reflexión de este trabajo tiende a exponer las diferentes aproximaciones sobre la cuestión social en los nuevos regionalismos, planteándose en particular los casos del Tratado de Libre Comercio de América del Norte, de la Unión Europea y los avances registrados en el MERCOSUR. Esta aproximación no busca introducir un análisis comparado, como sí se ha

\footnotetext{
9 En esta dirección -regionalismo como expresión de un modelo de desarrollo, o bien como modelo capitalistase inscribe el artículo de Francisco Aldecoa Luzárraga - Noé Cornago Prieto "El nuevo regionalismo y reestructuración del sistema mundial" Revista Española de Derecho Internacional vol. L, 1, Madrid, 1998.
} 
empleado en otros trabajos y documentos, porque no es el objetivo definido y tampoco pueden compararse ordenamientos con distintos marcos temporales que han definido diferentes densidades institucionales y normativas. De todas formas, lo que sí pueden señalarse son los énfasis otorgados, las opciones manifestadas y los instrumentos definidos por cada uno de los procesos de integración frente a la cuestión social. Uno de los aspectos básicos que se introducen al exponer estos tres procesos es la posibilidad de que se encaminen hacia criterios comunes de convergencia en lo que concierne la dimensión social y el comercio internacional en el espacio occidental.

\section{Internacionalización del mercado de trabajo y modelos de adaptación estatal: una aproximación al tema}

En este apartado se ubica primeramente la conformación de un mercado internacional de trabajo como parte del proceso de integración mundial. Con posterioridad, se plantea el eje del debate relacionado con las consecuencias que se derivan de la conformación de un mercado internacional del trabajo en los parámetros de competencia del comercio internacional. ${ }^{10}$ Finalmente se señala que a pesar de la internacionalización del mercado y de la vigencia de un solo modelo económico, el mercado expresa las diferentes concepciones que tienen las sociedades sobre la cuestión laboral en cuanto a los énfasis en los distintos derechos, los pilares sobre los cuales se construye el ordenamiento normativo, el papel del Estado y de los actores sociales. Estas variables expresan las diferencias existentes en las respuestas de adaptación de los Estados a los cambios estructurales planteados.

La integración mundial es un fenómeno que se encuentra impulsado por los cambios tecnológicos que se han producido y por la reducción del costo en

\footnotetext{
${ }^{20}$ Es claro que al ubicar de esta forma el tema no nos introducimos en el debate sobre el "fin del trabajo", ni tampoco sobre las consecuencias de la reestructuración productiva. Ambos aspectos se relacionan con este trabajo, pero este enfoque no trata especificamente ambos temas. Sobre el primer punto pueden consultarse, Jeremy Rikin El fin del trabajo. Nuevas tecnologias contra puestos de trabajo: el nacimiento de una nueva era, Paidós, Argentina, 1996; Claus Offe Contradicciones en el Estado de bienestar, Alianza, Madrid, 1990; Alain Gorz. Adiós al proletariado, El Viejo Topo, Barcelona, 1982. Sobre el segundo punto los teóricos de la regulación hari analizado con énfasis el tema. Véase entre otros, R. Boyer La teoria de la regulación. Un análisis crítico, Humanitas, Buenos Aires, 1989; A. Lipietz "Hacia una mundialización del fordismo" Teoría y Política, $n^{0} 7$, México 1992 y del mismo autor, "Acumulation, Crisis and the Ways Out", International Journal of Political Economy, vol. $18 n^{\circ}$ 2, 1998.Para tener una visión de conjunto, puede consultarse, Marcia Campillo - Enrique de la Garza, "Hacia dónde va el trabajo humano?" Nueva Sociedad n² 157, Caracas, septiembre - octubre 1998.
} 
materia de transporte y comunicaciones. Esta integración tiene como consecuencia en tanto ideal u objetivo final, un único mercado internacional y la libre movilidad de los factores productivos. La configuración de un mercado internacional se encuentra afectada en su conformación por el comercio internacional, los flujos de capital y la migración, en tanto conjunto de variables de la internacionalización económica.

Los tres aspectos señalados -comercio, flujos de capital y migraciones- atañen a la cuestión laboral en diferente medida. Sin embargo, tanto los flujos de capital como las migraciones tienen una conexión limitada en lo que concierne la internacionalización del mercado de trabajo. Los flujos de capital plantean el problema de la "globalización" financiera para los países en desarrollo y la posibilidad de atraer inversiones mediante una legislación restrictiva de derechos laborales. ${ }^{11}$ Las migraciones exponen la posibilidad de nuevos equilibrios laborales más limitados y la concreción de mercados paralelos con mínimo respecto de los derechos humanos y laborales. ${ }^{12}$ En cambio, el crecimiento del comercio internacional deriva necesariamente en la internacionalización del mercado de trabajo con las consecuencias que tiene en la aproximación del plano internacional y su condicionante del plano nacional..$^{13}$

Los dos primeros fenómenos afectan las relaciones laborales, pero no se introducen en las mismas, como sí lo hace el comercio internacional, al plantear un mercado mundial donde se expresan las ventajas "competitivas de las naciones", y el diseño de una nueva división del trabajo. El hecho de que el proceso no obedezca a una lógica rectilínea, en que los criterios de convergencia posibiliten determinados equilibrios inmediatos entre los distintos países del planeta, se debe a las diferentes políticas de los países por una parte y a las diversas respuestas tradicionales, regionales y culturales debido a la optimización geográfica, de tradición y cultura. ${ }^{14}$

\footnotetext{
"Las consecuencias que tienen para los países en desarrollo la globalización en tanto proceso y en tanto "ideología" es expuesto en el trabajo de Andrew Aixline "Regionalismo latinoamericano en la era de la globalización", en Lincoln Bizzozero -Marcel Vaillant (eds), La inserciōn internacional del MERCOSUR. ¿Mirando al Sur o mirando al Norte? Arca, Universidad de la República, Facultad de Ciencias Sociales, Fundaciôn Friedrich Ebert, Montevideo, 1996.

12 Sobre las consecuencias de la migración en el trabajo y sus repercusiones en el comercio pueden consultarse, Peter Stalker The Work of Strangers: A Survey of International Labour Migration, Oficina Internacional del Trabajo, Ginebra, 1994 y Sharon Russell - Michael Teitelbaum, International Migration and International Trade, Banco Mundial, Documento de Trabajo № 160, Washington 1993.

${ }^{13}$ El volumen del comercio internacional de bienes y servicios representó el $45 \%$ del PBI mundial. El $17 \%$ de la población activa de los países en desarrollo o de economías en transición de la planificaciôn centralizada, trabajaba en 1990 ligada al sector exportador. Véase Banco Mundial El mundo del trabajo en una economía integrada, Informe sobre el desarrollo mundial 1995, Washington 1995.
} 
En otros términos, la internacionalización y mundialización del mercado en esta fase del capitalismo no ha llevado a que se definan pilares comunes de funcionamiento y sustentación, sino a que surjan diferencias en las respuestas estratégicas y de pautas de valores que otorgan los Estados frente a los cambios estructurales. Esta afirmación sobre la diversidad de ejecución y de ajustes a los requisitos de funcionamiento de una economía de mercado no resulta novedosa. Varios autores habían planteado que la transición operada por las economías socialistas a comienzos de la década del ochenta, debido al incremento de la interdependencia no iba a derivar necesariamente en una economía de mercado, porque los contenidos en recursos institucionales, humanos y culturales conforman parte intrínseca del funcionamiento social y de sus resultados. ${ }^{15}$

$\mathrm{El}$ aspecto fundamental del debate actual es que estas respuestas de los Estados que conciernen al mercado laboral no son indiferentes al comercio internacional. Desde la perspectiva del sistema político y de la opinión pública de algunos países industrializados se observa que existen pautas muy disímiles en cuanto a la aplicación de las normas internacionales del trabajo y en cuanto al salario mínimo y que ello repercute en definitiva en un incremento de la desocupación. Por otra parte, la persistencia de prácticas laborales explotadoras en algunos países ha incrementado la presión de sectores de la sociedad civil de algunos países desarrollados para incorporar un capítulo de derechos sociales y laborales en el sistema de comercio internacional.

$\mathrm{El}$ hecho de que se planteen diversas respuestas no ocasionaría mayores dificultades si los criterios de convergencia y competitividad obedecieran a un modelo de desarrollo edificado sobre pilares comunes, lo cual podría entenderse si las sociedades tuvieran una misma concepción del mercado o bien si la interacción se gestara en el marco de un régimen internacional. Como esta aproximación de sociedades a través del mercado no reposa sobre las mismas bases, las diferencias se expresan en cada uno de los temas significativos y en la evolución de los debates, en los derechos y estructura de actores. Ello repercute obviamente en la definición de principios comunes en lo que

\footnotetext{
${ }^{14}$ No incluimos explícitamente las relaciones de interdependencia entre las respuestas, las cuales pueden incluirse en cualquiera de las mismas. Una manifestación regional que atañe a las relaciones laborales, el empleo y la expresión del comercio en la divisiön del trabajo, puede verse en Revue d‘Etudes Comparatives Est/Ouest, "Les transformations du travail et de l'emploi en Europe de l“Est depuis 1990", Volumen 29 n $^{0}$ 2, Centre National de la Recherche Scientifique, París, 1998.
} 
concierne la vinculación de la cuestión laboral con el comercio para modificar el régimen internacional. ${ }^{16}$

Las diferencias que tienen las sociedades sobre el mercado se expresan en el valor asignado al mismo en función del orden social. En ese sentido, si bien todas las sociedades apelan a distintos medios -coercitivos, utilitarios, simbólico-normativos- para mantener el orden social, los énfasis y prioridades que le asignan a los mismos delimitan la concepción de base que se tenga del mercado. ${ }^{17}$ Las sociedades pueden otorgarle un contenido más o menos colectivo al mercado a través de disposiciones autoritarias o a través de disposiciones normativas o bien enfatizar los límites del orden social y el contenido libertario que puede expresarse en el mercado.

Esta percepción que tiene la sociedad del mercado condiciona en buena medida otros dos aspectos sobre los cuales se centran varios enfoques y aproximaciones al tema: el lugar que tienen los derechos laborales en las sociedades, tanto en su relación con los otros derechos humanos, como en su vínculo con el mercado; y el grado de regulación que debe tener el mercado laboral por parte del Estado. ${ }^{18}$

El primer aspecto-lugar que ocupan los derechos laborales en las sociedades- nos remite a dos temas previos: la relación del derecho laboral con los derechos humanos y la importancia que se le asigna al incluir otros derechos individuales y colectivos. En general los enfoques que toman como punto de partida el derecho laboral en el estudio del vínculo con el comercio, centran el análisis en el seguimiento de la ratificación y cumplimiento de los conve-

${ }^{35}$ Véase al respecto, C. Dyke Filosofía de la economía, Paidós, Argentina, 1983. las dificultades en el funcionamiento del mercado son visibles todavía en algunos países de Europa central y en Rusia.

${ }^{16}$ Acá se plantea la transformaciôn del régimen internacional del comercio, a través de la inclusión de la cuestión laboral. Tambiến puede plantearse la creación de un régimen internacional específico que contenga principios y reglas sobre la internacionalización y mundialización de la cuestión laboral.

${ }^{17}$ Amitai Etzioni, La nueva regla de oro. Comunidad y moralidad en una sociedad democrática, Paidós, Barcelona - Buenos Aires, 1999.

${ }^{\text {¿ }}$ Los debates sobre el grado de intervención del Estado atienden no solamente a la esfera del derecho colectivo del trabajo, sino también a la negociación colectiva, que se expresa a través de las partes. Ello significa en definitiva que los cambios se expresan en las relaciones colectivas y en las relaciones individuales de trabajo. Véase en ese sentido, Jorge Rosenbaum, "El debate contemporáneo sobre reglamentaciōn y desregulación del derecho del trabajo", RELASUR № 8 , OIT/Ministerio de Trabajo y Seguridad Social de España, Montevideo, 1995 y Arturo Bronstein, "Cambio social y relaciones de trabajo en América Latina: Balance y perspectivas", Revista Internacional del Trabajo, vol. 114, n으 2, OlT, Ginebra, 1995. El análisis especííco plantea dificultades diversas derivadas de la visualización de los cambios sobre la base de una interdependencia compleja de temas, sectores y actores, lo cual deriva en una diversidad de respuestas que se expresan en el mercado de trabajo. Las opciones desde una perspectiva internacional son señaladas por Ulrich Walwei, Flexibilización y regulación del mercado de trabajo: experiencias internacionales y opciones, Serie PROSUR, Fundación Friedrich Ebert, Buenos Aires, 1996. 
nios internacionales del trabajo firmados por los países. ${ }^{19}$ Esta aproximación que resulta pertinente en cuanto a la observancia del cumplimiento de los convenios, no nos permite adentrarnos en la respuesta que pueda dar el Estado cuando se plantea el tema de la internacionalización del mercado laboral.

El segundo punto de partida concierne los criterios ordenadores del Derecho del Trabajo, lo cual se manifiesta en lógicas contrapuestas entre la intervención del Estado para asegurar derechos y acordar normas y parámetros de funcionamiento que otorguen principios uniformes y la que insiste en otorgar mayor autonomía a las partes, lo cual posibilitaría mejores desempeños del conjunto de la sociedad..$^{20}$ Las dos lógicas se basan en fundamentos diferentes sobre el papel que deben desempeñar los actores y en particular el Estado; el grado de orden necesario para la sociedad y el grado de autonomía permisible para que la misma no se atomice en múltiples relaciones; y en definitiva sobre los efectos que se derivan para la persona (empleo y mejores desempeños).

Los cambios o ajustes que pueda tener la lógica que acompañó el proceso formativo del derecho del trabajo expresado en la concepción del garantismo social y los criterios y contenidos que puedan acompañar las pautas de flexibilidad que se impulsan, se encuentran incorporados en las posiciones de actores de los distintos niveles en que se articulan las sociedades humanas. ${ }^{21}$ Las disimilitudes en tomo a la evolución del Derecho del Trabajo y a las posibilidades que otorga una mayor o menor regulación o flexibilidad en el mercado laboral, constituyen una expresión de las diferentes posiciones y valores entre las sociedades. ${ }^{22}$

Esta aproximación metodológica plantea que las respuestas de los Estados a esta nueva fase de internacionalización del mercado del trabajo, se arti-

\footnotetext{
19 Véanse al respecto los trabajos de Lee Swepston, "Desarrollo de las normas sobre derechos humanos y libertad sindical mediante el control de la OIT" y Nicolas Valticos "Nomas internacionales del trabajo y derechos humanos. ¿Cómo estamos en vísperas del año 2000?" en Revista Internacional del Trabajo, vol. 117, número 2, dedicada al tema de los derechos laborales y derechos humanos, Ginebra, 1998/2.

${ }^{20}$ Entre las dos lógicas se expresan los cambios que se procesan en las relaciones laborales para adecuar las mismas a las exigencias de la competitividad, a los requerimientos del mercado y a las necesidades planteadas por las organizaciones sindicales y los otros actores de la sociedad. En materia de análisis específicos sobre la evolución de las relaciones laborales pueden consultarse los trabajos de Adrián Goldin, El Trabajo y los mercados. Sobre las relaciones laborales en Argentina, Eudeba, Buenos Aires, 1997; J. M. Rodrïguez (coord)- Beatriz Cozzano -Graciela Mazzuch- María del Lujān Pozzolo, ¿Hacia un nuevo modelo de relaciones laborales? De la apertura política a la apertura económica, Unuguay 1985-1998, Ed. Trilce, Universidad Católica, Montevideo, 1998.

2: La evolución reciente de estos debates expresados en los órdenes legales de América Latina puede leerse en Arturo Bronstein, "Reforma laboral en Amêrica Latina: entre garantismo y flexibilidad", Revista Internacional del Trabajo, vol. 116 nำ1. Oficina Internacional del Trabajo, Ginebra, 1997.

${ }^{22}$ Las consecuencias que tiene ese debate en los aspectos prácticos de intervención del Estado y las negociaciones colectivas puede ser consultado en Jorge Rosenbaum, "Gl debate contemporáneo sobre reglamentación y desregulación del derecho del trabajo", RELASUR, nº 8, OIT/Ministerio de Trabajo y Seguridad Social de España, Montevideo, 1995.
} 
culan desde tres dimensiones que no siempre resultan convergentes: la que se refiere a la concepción que tenga la sociedad del mercado; la del lugar que ocupen los derechos laborales en la sociedad y finalmente al grado de intervención del Estado y de regulación del mercado laboral. Estas respuestas deben ser mediatizadas por el plano de respuesta estratégico, en que el Estado responde de acuerdo a las prioridades externas, los instrumentos y compromisos asumidos.

La articulación de las tres dimensiones no resulta sencilla para establecer una tipología de respuestas. Sin embargo, pueden asumirse tres modelos a partir de la concepción que haga la sociedad del mercado y de su inclusión en el orden social: autoritaria, liberal y comunitaria. Los tres modelos posibilitan incluir las respuestas de las otras dos dimensiones bajo los mismos supuestos, aun cuando no siempre sean convergentes con una orientación final. La tipología abarcando los tres modelos y los dos planos se presentaría de la siguiente manera:

\section{Plano de la respuesta socio-cultural}

Dimensiones de la Respuestas del Estado a la respuesta internacionalización del mercado laboral

\begin{tabular}{|l|l|l|}
\hline $\begin{array}{l}\text { CONSIDERACIÓN DEL MERCADO POR } \\
\text { LA SOCIEDAD Y ORDEN SOCIAL }\end{array}$ & DERECHOS LABORALES & \multicolumn{1}{|c|}{$\begin{array}{c}\text { INTERVENCIÓN } \\
\text { ESTADO / REgulación }\end{array}$} \\
\hline $\begin{array}{l}\text { Autoritaria (Salvaguarda } \\
\text { del orden por parte del } \\
\text { Estado; énfasis en instru- } \\
\text { mentos restrictivos). }\end{array}$ & $\begin{array}{l}\text { Derechos colectivos } \\
\text { en función del Estado. }\end{array}$ & $\begin{array}{l}\text { Más intervención } \\
\text { y regulación. }\end{array}$ \\
\hline $\begin{array}{l}\text { Libertaria (limitación } \\
\text { del alcance de Orden } \\
\text { social; énfasis de instru- } \\
\text { mentos utilitarios). }\end{array}$ & $\begin{array}{l}\text { Derechos individuales; } \\
\text { derechos consumidor. }\end{array}$ & $\begin{array}{l}\text { Autonomía de las partes } \\
\text { y más flexibilidad. }\end{array}$ \\
\hline $\begin{array}{l}\text { Comunitaria (Orden } \\
\text { social negociado a partir } \\
\text { de valores socio-cultu- } \\
\text { rales de la comunidad; } \\
\text { énfasis en instrumentos } \\
\text { simbólicos y culturales). }\end{array}$ & $\begin{array}{l}\text { Derechos colectivos } \\
\text { en función de sociedad. }\end{array}$ & $\begin{array}{l}\text { Capacidad del } \\
\text { sistema político } \\
\text { en tanto mediador. }\end{array}$ \\
\hline
\end{tabular}

\section{Plano de la respuesta estratégica}

Limitaciones externas

Definición de prioridades por áreas y sectores

Intervención en regímenes internacionales 
La interacción de estos dos planos puede a veces resultar confusa, por el hecho de que el primer plano ahonda en una lógica que parte de la sociedad y se traslada hacia el exterior, mientras la segunda incorpora la dimensión realista de las condiciones, prioridades e inserción del Estado en regímenes internacionales y diversos acuerdos regionales. Lo que resulta relevante es el hecho de que la internacionalización del mercado laboral no deparará por sí un equilibrio o una aproximación entre los Estados en la cuestión laboral, por lo que ello continuará afectando el mercado de productos. Solamente en el caso de que la respuesta mayoritaria se ubicara en una concepción libertaria del orden, lo cual derivaría en restricciones al alcance del orden social, los contenidos y costos laborales podrían ser equilibrados por el mercado. Pero ahí estaríamos en otro escenario y el punto delicado a dilucidar tendría relación con el alcance del orden social.

\section{El régimen de comercio internacional y la "cláusula social"}

El apartado anterior hizo visible la diversidad de respuestas del Estado frente a los cambios que apareja la internacionalización del mercado laboral por el crecimiento del comercio internacional. En este apartado se analizarán las dificultades para concretar en los organismos internacionales determinados principios comunes atinentes a la "cláusula social", en particular a través de la reforma o el cambio del régimen de comercio internacional. Para ello se tratará en primer término, el renovado interés que ha suscitado la vinculación de la cuestión social con el comercio internacional. Posteriormente se planteará el énfasis otorgado por la política exterior de Estados Unidos y su relación con la sociedad civil. Finalmente se expondrán las dificultades existentes para avanzar sobre el tema en el marco multilateral.

El tema de la vinculación del comercio con las normas internacionales del trabajo no es novedoso: estuvo planteado en la Carta de La Habana que creó la Organización Internacional del Comercio, en el sistema post-Segunda Guerra Mundial y ya se había expresado anteriormente con el inicio de la Organización Internacional del Trabajo. ${ }^{23}$ En su momento, la Carta de La Habana no

${ }^{23}$ Eddy Lee, "Mundializaciōn y normas del trabajo. Puntos del debate", Revista Internacional del Trabajo, vol. $116 \mathrm{n}^{\circ} 2$ 2, Ginebra, 1997. 
fue ratificada por el Congreso de Estados Unidos, por lo que la práctica internacional derivó desde entonces a diferenciar la cuestión laboral de la administración del comercio. Tampoco son novedosos los intentos que realizó en su momento Estados Unidos para adoptar determinados principios y reglas internacionales sobre el derecho de la mano de obra, en el seno de las rondas multilaterales de comercio. ${ }^{24}$

Sin embargo, en las últimas décadas se ha producido una transición en la relación entre el Estado y la sociedad civil, que ha alterado las bases contractuales sobre las que se edificó el orden de post-guerra mundial. En particular, la interdependencia compleja ha modificado varios supuestos que posibilitaron la separación práctica del comercio y el trabajo. En primer lugar, el supuesto de base de que el crecimiento del comercio internacional sobre la base de las ventajas comparativas, entre las cuales se incluían las diferencias nacionales, suponía el advenimiento del progreso económico. Esta relación fue posible que se desarrollara sin mayores objeciones en el sistema bipolar como "arma estratégica" porque la perspectiva liberal ponía el énfasis en la libertad de regulación por el mercado. En esa dirección el crecimiento económico posibilitaba la mejora en las condiciones de trabajo que se expresaba necesariamente en un progreso social. Con la caída del muro de Berlín y el triunfo de un modelo económico la relación entre el crecimiento del comercio y el progreso social dejó de tener el sentido estratégico que tuvo en las décadas del sistema bipolar. De esta forma, la revolución tecnológica en las comunicaciones y la aproximación global del mundo en un solo modelo básico, mostró que la diversidad de aproximaciones al mercado por parte del Estado y las sociedades, no derivaba necesariamente en mejores condiciones sociales.

La intervención de distintas organizaciones civiles y sindicales y la mayor sensibilidad política y social en algunos países de mayor desarrollo frente a determinadas situaciones sociales y laborales se conjugaron con el

\footnotetext{
${ }^{24}$ El Congreso de Estados Unidos recomendó al gobierno el apoyo activo a todo esfuerzo multilateral para adoptar reglas internacionales sobre el derecho de la mano de obra, en 1974 y en la Ronda Tokio en 1979. Con posterioridad, en el ciclo de la Ronda Uruguay del GATT, Estados Unidos solicitó en cuatro ocasiones entre 1986 y 1994 la inclusión de una cláusula social y en particular el establecimiento de un grupo de trabajo para estudiar los lazos entre el comercio y los derechos fundamentales de los trabajadores. Véase, GATT, "Communication des Etats-Unis concernant le rapport entre les normes de travail internationalement reconnues et le commerce international", Activitës en 1988, Tour d"horizon annuel des travaux du GATT, Ginebra, 1998; GATT, "Proposition des Etats-Unis concernant l'établissement d"un groupe de travail sur les normes de travail", Activités en 1989, Tour d"horizon annuel des travaux du GATT, Ginebra 1990.
} 
compromiso de Estados Unidos en la inclusión de un capítulo social en el régimen de comercio internacional. Si bien el debate sobre las consecuencias económicas de una armonización de normas se instaló en distintos foros sin que se llegara a una definición clara y convincente sobre los efectos negativos o positivos de la misma, ${ }^{25}$ lo que interesa resaltar en esta visión son dos aspectos que circunscriben la orientación futura: la opción política de Estados Unidos en sus relaciones externas de otorgar prioridad a la "ampliación democrática" y la aproximación de distintos actores políticos y de la sociedad civil de algunos Estados en particular, a las orientaciones en las políticas sociales estatales que se puedan definir. ${ }^{26}$

El compromiso con la democracia en la política exterior de Estados Unidos ha sido incorporado con particular énfasis desde los años noventa. Al respecto, la Iniciativa Bush para las Américas tenía un doble pilar sobre el cual proyectó el mensaje: el libre mercado para el comercio y las inversiones y la democracia postulando que el continente americano iba a ser el primer continente libre y democrático del mundo. Esta opción de política exterior proyectó hacia el interior de la sociedad un canal de intercambio en materia de política exterior y por otra parte en las definiciones de política comercial, consolidó una vía de "unilateralismo agresivo" al incluir aspectos políticos y sociales en la consideración de los acuerdos comerciales. ${ }^{27}$

La revolución de las telecomunicaciones ha posibilitado la aproximación de los sectores políticos y sociales a las distintas expresiones que se manifies-

${ }^{25}$ El debate sobre si es necesaria una armonización de normas del trabajo debe insertarse en el debate más general sobre la pertinencia de incluir en los acuerdos de liberalización comercial otras reglas que no sean las estrictamente comerciales. Como veremos, este aspecto del debate surgió con énfasis en la firma de los acuerdos paralelos al Tratado de Libre Comercio de América del Norte en los Estados Unidos. En cuanto a los efectos económicos de la armonización, si bien se señala que la nivelación asegura determinadas reglas equitativas y el desarrollo de las ventajas competitivas, los análisis efectuados no resultan convergentes en cuanto a la extensión y profundidad de la armonización y además no enfatizan suficientemente la variable cultural. Para profundizar en este punto, véase Jagdish Bhagwati, -Robert Hudec, Fair trade and harmonization: Prerequisites for free trade?, 2 volúmenes, MIT Press, Cambridge - Londres, 1996, citado por Eddy Lee, "Mundialización y normas del trabajo...", op. Cit. Véase también, Paul Krugman, "What should trade negotiators negotiate about?", Journal of Economic Literature vol. 35, Nashville, 1995.

${ }^{26}$ Lo cual en definitiva nos lleva a ubicar el tema en la interacción de comunidades complejas en un sistema, por lo que el debate sobre la universalidad de las normas del trabajo y el regionalismo debe circunscribirse a los principios prácticos y las consecuencias derivadas de opciones de política. La ubicación del debate en sus adecuados têrminos en un contexto político puede leerse en Diana Brand- Ralf Hoffmann, "Le débat sur l'introduction d'une clause sociale dans le système commercial international: quels enjeux?", Problèmes Economiques, noviembre 1994. Una respuesta "atrincherada" desde una perspectiva institucional al tema la otorga Nicolas Valticos, "Normas internacionales del trabajo y derechos humanos. ¿Cómo estamos en vísperas del año 2000" Revista Internacional del Trabajo, vol. 117, $n^{\mathbf{0}} 2$, Ginebra 1998, cuando cuestiona los enfoques regionales que enfatizan la especificidad cultural de los derechos humanos. 
tan en el mundo y a las inflexiones del Estado en sus políticas públicas. De esta forma, si bien el devenir de la información y la multiplicación de imágenes y noticias puede llevar a obviar y descartar sucesos como mecanismo protector y de defensa, la aproximación al "otro" permite potencialmente el desencadenamiento de acciones diversas que pueden originar consecuencias públicas y privadas.

En segundo término la concepción del crecimiento económico se basó en los supuestos del incremento del comercio y del pleno empleo, lo cual dejó de ser valedero, al menos en lo que se refiere a que el crecimiento económico aseguraba el empleo, ya que creció el desempleo estructural y no puede ser absorbido por nuevos movimientos económicos. Al respecto resulta significativo el incremento del nivel de desocupados en los países desarrollados y los niveles de desocupación entre los jóvenes que dan muestra de problemas estructurales. El "Libro Blanco" de la Comisión Europea señala como cifra optimista un nivel de desocupación del $8 \%$ para el año 2000, lo cual llevaría el porcentaje a los niveles del año 1991.28

Si bien el incremento del desempleo y el pasaje de las relaciones laborales "modernas" a relaciones a tiempo parcial y temporales ha llevado a debates significativos sobre la finalidad y sentido del trabajo en tanto actividad humana, ${ }^{29}$ lo que resulta pertinente destacar es que la sensibilidad sobre el tema del empleo en tanto actividad humana remunerada, ha crecido en la opinión pública de los países desarrollados, provocando con ello repercusiones en la comunicación del sistema político con la ciudadanía y en las relaciones externas.

La sensibilidad acrecentada de la opinión pública de los países desarrollados sobre los efectos del desempleo en las sociedades, ha tenido derivaciones

\footnotetext{
${ }^{27}$ La relación entre los contenidos "agresivos" de la política comercial de Estados Unidos y el Acuerdo de Libre Comercio de América del Norte puede leerse en Pierre Martin, "La nouvelle dynamique de la politique commerciale aux Etats-Unis et l'Accord de libre-ëchange nord-américain" Etudes Internationales, vol. XXIV número 4, Centre Québécois de Relations Internationales, Université Laval, Quebec, diciembre de 1993. Véase también, Lincoln Bizzozero, Canadá y la integración en América del Norte: respuestas y desafios Biblioteca Norte-Sur, Argentina, 1996.

${ }^{28}$ Cf. Ulrich Walwei Instrumentos de la política de empleo en la Unión Europea, Cuaderno número 3 , Fundación Friedrich Ebert, Buenos Aires, agosto de 1995.

${ }^{29} \mathrm{Al}$ respecto podría señalarse que uno de los debates concierne al objetivo del pleno empleo en un mundo altamente productivo, que de por sí genera más desempleo. Algunas reflexiones que parten de la historia apuntan a que el pleno empleo tuvo consistencia en un corto período en la historia de la humanidad, por lo que la reestructuración de la sociedad humana debería pasar por la actividad y no por el empleo. Uno de los libros que colaboró con los debates sobre estos tópicos fue el de Jeremy Rifkin, El fin del trabajo. Nuevas tecnologías contra puestos de trabajo: el nacimiento de una nueva era, Paidós, Buenos Aires, 1996.
} 
específicas en Estados Unidos y algunos países europeos en lo que se refiere a las relaciones laborales y las condiciones de empleo. Algunas denuncias sobre el trabajo esclavo en empresas estadounidenses radicadas en América Central y las demandas acrecentadas para imponer un etiquetado social por parte de organizaciones de la sociedad civil no son sino algunas de las manifestaciones novedosas de una sensibilidad sobre los derechos humanos que se conjuga con las condiciones de trabajo y sus consecuencias en las sociedades nacionales. ${ }^{30}$ De esta forma, las bases para vincular la condición social en general y las relaciones laborales en particular con el comercio internacional pudieron ser incorporadas en los países desarrollados de Occidente como consecuencia de una mayor sensibilidad de las sociedades civiles frente a las decisiones políticas y a determinadas violaciones de derechos humanos.

La inclusión del componente democrático y social en las políticas exteriores de Estados Unidos y de la Unión Europea posibilita una convergencia en el objetivo final de fomentar el ejercicio de los derechos políticos, cívicos e individuales para asegurar la integridad de la competencia política y de la participación en los sistemas nacionales. Debe hacerse notar que la convergencia en el objetivo final no diluye las diferencias existentes en los instrumentos que se utilizan para la aplicación de la cláusula. En particular, la política exterior de Estados Unidos enfatiza específicamente la relación entre la cláusula social, las relaciones laborales y la condición democrática, mientras la "cláusula democrática" que ha incluido la Unión Europea en los convenios de cooperación ha sentado las bases para mantener un diálogo político de manera paralela a la cooperación en sus diferentes manifestaciones (económica, tecnológica, educativa, cultural).

De esta manera, Estados Unidos ha sido el portavoz en el sistema de comercio internacional para vincular las relaciones laborales con el comercio y por ende para plantear determinados pilares con la finalidad de una armonización normativa. En ese sentido, las acciones de política exterior de Estados Unidos no se alejan de otras posiciones e iniciativas en diversos dominios que posibilitaron el nacimiento o las modificaciones necesarias a regímenes internacionales. Sin embargo, las actuales derivaciones tanto de política doméstica en Estados Unidos, en que las mayorías republicanas en el Congreso

3o Sobre el etiquetado social un artículo de interés es el de lanet Hilowitz, "Consideraciones sobre el etiquetado social en la lucha contra el trabajo infantil", Revista Internacional del Trabajo, vol. 116, Oficina Internacional del Trabajo, Ginebra, 1997/2. 
cuestionan la idea de vincular el comercio con otros aspectos, así como las dificultades en avanzar en la aceptación de una modificación de las bases sobre las cuales funciona la lógica comercial internacional en los organismos internacionales y en general en la comunidad internacional, han llevado a que el tema se manifieste en el nivel doméstico de la política de Estados Unidos y en el regional como resultado de la convergencia entre la sociedad civil y el gobierno en la supervisión de los efectos del libre comercio, sin que necesariamente tenga efectos, al menos inmediatos, en el ámbito regional.

Este movimiento acumulativo de tendencias que facilita la política de Estados Unidos, a través del Ejecutivo con los límites y condiciones del Congreso, parece haberse transformado en uno de los rasgos actuales de la interacción entre las políticas exteriores de Estados Unidos y el sistema internacional. Las negociaciones de acuerdos de libre comercio con Canadá y posteriormente con México y otras iniciativas en momentos en que se desarrollaba la Ronda Uruguay; el desarrollo del Acuerdo de Libre Comercio de las Américas por parte del Ejecutivo sin que el Congreso haya votado el "fast track", son algunas de las manifestaciones señaladas que muestran no solamente la importancia que tienen los equilibrios de Poderes y de visiones de la política de Estados Unidos en el sistema internacional, sino también el hecho de que las diferencias existentes en cuanto a la interpretación del sistema y del papel que debe cumplir Estados Unidos afectan las elites políticas. ${ }^{31}$

Además de la concepción "neoclásica" de no vincular el comercio con otros temas, dos núcleos de ideas afectan el posible desarrollo de este tema en lo que concierne la política exterior de Estados Unidos. Una de las ideas-fuerza que está afectando los lineamientos de política exterior de Estados Unidos tiene relación con el hecho de que los cambios que se están produciendo afectan horizontalmente al conjunto de naciones del planeta y va a provocar una "guerra entre distintos sectores generadores de riqueza". ${ }^{32}$ Las derivaciones de esta concepción llevan a considerar el papel de Estados Unidos en facilitar esta transición y marcar el camino, sin que desvíen esfuerzos hacia la protec-

\footnotetext{
3t También puede interpretarse esta situación como parte de una estrategia de política exterior de Estados Unidos, que posibilita "ganancias" relativas en diversos frentes mientras se van resolviendo los temas y se ajustan los regimenes. A los efectos de este análisis, las consecuencias en el objeto de estudio son similares, aun cuando considero que la transición también ha afectado los supuestos que posibjlitaban las bases consensuales de la politica exterior de Estados Unidos.

32 Véase en esa dirección los trabajos de Alvin Toffler entre los cuales resulta particularmente de interés la lectura del libro El cambio del poder. Conocimientos, bienestar y violencia en el umbral del siglo XXI, Plaza \& Janés ed., España, tercera ediciön, 1991.
} 
ción de los sectores industrial y el agrícola. ${ }^{33}$ La segunda idea-fuerza que puede afectar la política exterior de Estados Unidos en este tema, concierne a la definición de la identidad estadounidense y al vínculo que pueda tener con el trabajo y con el papel de Estados Unidos en el mundo. En ese sentido, un lineamiento de políticas sociales propuesto por integrantes de la Administración Clinton, ha sido capacitar al ciudadano de Estados Unidos y calificar el trabajo con la finalidad de definir un estatuto de país calificado y diferenciado en el sistema internacional. Las consecuencias de esta idea-fuerza van en una dirección diferente a las derivaciones planteadas anteriormente en un doble sentido: por una parte, se busca aproximar a los diversos sectores de la sociedad estadounidense para reaccionar conjuntamente desde una perspectiva común; por otra parte, se visualiza la continuidad de un sistema internacional cuyas sociedades pueden plantear opciones diferenciadas frente al sistema internacional, posibilitando de esta forma una articulación del mismo a través de esas diferencias. ${ }^{34}$

Diferentes factores explican la situación actual de estancamiento del tema en las instancias y ámbitos internacionales. Por una parte el factor temporal vinculado al hecho de que se aproxima la Ronda del Milenio y hacia esa instancia se está centrando la atención y las energías de las administraciones, pero también, y sobre todo, de las instancias multilaterales internacionales y regionales y de los foros y cumbres regionales.

En segundo término, los diferentes objetivos y perspectivas de la política exterior de Estados Unidos, que busca contemplar los esfuerzos de ampliar la democracia con una mayor liberalización del comercio que tenga en cuenta las condiciones laborales. Como ya se señaló, los equilibrios institucionales por una parte, el insuficiente apoyo del sistema político por el otro, y finalmente las diferencias existentes en el seno de la sociedad civil, sobre todo entre empresarios y sindicalistas, en lo que concierne la extensión y profundidad del vínculo relaciones laborales-comercio, han llevado a que el tema se mantenga en la agenda gubernamental, sin que sobresalga como una prioridad de política en el presente.

\footnotetext{
33 Esta es una de las ideas -fuerza que incide en las definiciones del presupuesto y en las derivaciones de la politica exterior. Al respecto, cada una de las principales lógicas sobre la seguridad internacional y sobre el papel de los Estados Unidos cuenta con apoyos especíícos políticos y sociales, lo cual repercute en los contratos y solicitudes del Pentágono a los sectores empresariales. Véase al respecto, Alain Joxe, "Représentation des alliances dans la stratégie américaine", Politique Etrangère 2/97, Institut Français des Relations Internationales, París, 1997.

${ }^{34}$ Véase al respecto el libro de Robert Reich, El trabajo de las Naciones. Hacia el capitalismo del siglo XXI, Ed. Vergara, Buenos Aires, 1993.
} 
En tercer lugar, la propia reflexión que se ha hecho desde los organismos internacionales ha derivado en otorgar continuidad a los lineamientos seguidos hasta ahora en cuanto a la división de tareas entre los mismos. En ese sentido, la supervisión del cumplimiento sobre los principios y derechos fundamentales en el trabajo correspondería a la Organización Internacional del Trabajo, y por otra parte, la supervisión de que se cumplan los requisitos del libre acceso al mercado, lo que excluye un control de «calidad social» del producto por una parte y de que no exista una situación de dumping por disminución del precio del producto en el mercado externo, lo cual descarta la inclusión y evaluación del «costo social» por otra parte, quedarían a cargo de la Organización Mundial del Comercio.

En cuarto lugar, los distintos estudios realizados por organismos internacionales que se han sumado al debate, como el Banco Mundial y el Fondo Monetario Internacional, señalan claramente que el vínculo de la cláusula social con el comercio internacional tendría efectos perjudiciales para los países en desarrollo, tanto en materia de desempleo y subempleo, debido a que el incremento del costo laboral sin crecimiento económico y calificación del personal provocaría un retraimiento de las inversiones y de las empresas, como en el comercio exterior, por la disminución de las exportaciones. En definitiva, esos análisis marcan más bien la pauta de que el vínculo de la cláusula social con el comercio redundaría en una protección de los mercados de los países desarrollados y en particular de Occidente. ${ }^{35}$

Finalmente, los estudios realizados no son concluyentes en el sentido de que la conexión de la cláusula social en el régimen de comercio internacional facilitaría la armonización del régimen y por otra parte otorgaría transparencia y equidad, sin costos suplementarios a los países en desarrollo. En ese sentido, si bien los énfasis en el respeto al núcleo de derechos laborales resulta relevante a los efectos de las condiciones laborales, no resulta claro el hecho de vincularlo con el comercio, a los efectos de los contralores internos, sobre todo cuando los convenios de la OIT han sido ratificados por buena parte de los países del sistema internacional. Acá se introduce otro elemento de debate en el

\footnotetext{
35 El trabajo del Banco Mundial citado plantea la dificultad que surge de vincular el comercio con los derechos del trabajo. Los trabajos de Keith Maskus, Could Core Labor Standards be Imposed Through International Trade Policy?, Washington DC, Banco Mundial, Policy Research Working Paper 1817, agosto 1997 y de Stephen Golub, International Labor Standards and International Trade Fondo Monetario Internacional, Working Paper WP/97/37, abril de 1997, enfatizan las repercusiones negativas que tendrian para algunos países en desarrollo la aplicación de determinadas reglas en el comercio internacional.
} 
sentido de la supervisión de esos derechos y la relación con la Organización Internacional del Trabajo, cuyo sentido escapa a los límites de este trabajo.

Lo expuesto en este apartado plantea las dificultades en definir cambios en el régimen del comercio internacional en lo que concierne el vínculo con las condiciones sociales. Los cambios pueden provenir del poder hegemóni$\mathrm{co}$, de una coalición de potencias, de inflexiones de las instituciones internacionales o por cambios que se producen en las propias condiciones del régimen. En este apartado se planteó que los avances de la política exterior de Estados Unidos en el sentido de vincular el comercio con las condiciones de trabajo, quedaron por el momento relegados en los ámbitos internacionales, pero que continúan presentes como temas de la agenda y que además han sido introducidas en el ámbito regional. Por otra parte, las instituciones internacionales han incluido el tema en sus análisis, pero sus enfoques han mantenido la división funcional de trabajo existente como pauta de funcionamiento, ocupándose la OMC de las condiciones para la liberalización del comercio, sin que ingresen los principios y reglas laborales y sociales en esa consideración. Finalmente, varios estudios y análisis señalan la dificultad que plantea una armonización de normas a aplicarse en el régimen de comercio internacional, aun cuando se reafirma la existencia de un núcleo duro de derechos colectivos del trabajo, que continúan siendo supervisados por la OIT. ${ }^{36}$

De esta forma, si los avances en materia de un régimen internacional que pueda vincular el comercio con las condiciones sociales no han tenido resultados en el plano internacional y si el mercado no asegura una armonización natural de las respuestas y un determinado equilibrio, sino que se produce el efecto contrario, queda por ver si los regionalismos cumplen un determinado papel en el sentido de que puedan constituir respuestas diferenciadas y específicas frente a los cambios que se procesan en la estructura del sistema internacional y de ahí configurar distintas articulaciones de las sociedades en la mundialización.

${ }^{36}$ Hillary Kellerson, "La declaración de la OlT de 1998 sobre los principios y derechos fundamentales: un reto para el futuro", Revista Internacional del Trabajo, vol. 117 núm. 2, OlT, Ginebra, 1998/2. 


\section{EI TLCAN, la Unión Europea y el MERCOSUR frente a la cuestión social}

En el apartado anterior se visualizó la dificultad en llegar a determinadas condiciones que posibilitaran un cambio en el régimen de comercio internacional, mediante la inclusión de la cláusula social. Los avances de la política exterior de Estados Unidos al respecto, la sensibilidad acrecentada de algunos países desarrollados y el tratamiento del tema por parte de los organismos internacionales, ha llevado a colocar la cuestión en la agenda internacional. En este punto se verá primeramente la pertinencia de tomar como marco analítico a los regionalismos en la mundialización, para luego plantear las diferentes aproximaciones que se tienen frente a la inclusión de la cuestión social en el comercio internacional, en el Tratado de Libre Comercio de América del Norte, la Unión Europea y el MERCOSUR.

La literatura sobre los regionalismos ha partido básicamente de dos núcleos conceptuales: en tanto elaboración de los regímenes, el regionalismo posibilita una adaptación del espacio a las orientaciones que provienen del sistema internacional, en particular a través de la disminución de costos de transacción derivados del intercambio con factores y actores transnacionales; en tanto respuesta a la búsqueda de inserción competitiva frente a la globalización, los regionalismos se articulan con el sistema multilateral de comercio definiendo distintos ejes de cooperación y conflicto en sus posiciones. ${ }^{37}$

Uno de los problemas que han tenido los analistas frente al tema de los nuevos regionalismos es el de trascender los enfoques provenientes de una visión disciplinaria muy especializada, que no contempla la relación entre los problemas planteados por la seguridad y la apertura del mercado en la globalización y la interacción entre la esfera pública y los actores privados con esos dos núcleos. ${ }^{38}$ Por otra parte, los estudiosos deben superar los análisis que presuponen determinados escenarios a partir de un marco concep-

\footnotetext{
37 El par cooperación-conflicto puede originarse en la base misma del sistema de comercio internacional, a través de la disyuntiva regional-multilateral; en la relación entre áreas geográficas y por núcleos temáticos o sectoriales (propiedad intelectual, patentes, entre otros). Para una visión del tema en su par de opuestos regional-multilateral, mientras se negociaba la Ronda Uruguay del GAT, véase Marcel Vaillant-Tabaré Vera, "Bloques comerciales versus multilateralismo: Mercosur, el caso de un pequeño bloque Sur-Sur", en Lincoln Bizzozero-Klaus Bodemer-Marcel Vaillant (eds), Nuevos regionalismos: icooperaciōn o conflicto?, Ed. Nueva Sociedad -Universidad de la Repüblica.Fundación Friedrich Ebert de Uruguay, Caracas, 2994.
} 
tual definido ex-ante y las aproximaciones que otorgan prioridad a las secuencias del "relato" de la historia presente. ${ }^{39}$

Luego que culminara la Ronda Uruguay del GATT y se llegara a la convicción analítica de que el sistema multilateral de comercio no iba a descomponerse frente a una "guerra comercial" entre bloques, de que los nuevos temas de seguridad se incorporaban en las agendas temáticas de distintas organizaciones regionales, de que los Estados llegaban a nuevos compromisos con diferentes organizaciones internacionales y regionales y que también abrían el camino a nuevos pactos con los actores de la sociedad civil y con otros actores sub-nacionales y transnacionales, los analistas de las relaciones internacionales comenzaron a analizar el concepto de regionalismo y su pertinencia analítica en las relaciones internacionales.

Dejando de lado las revisiones teóricas que hacen hincapié en determinadas continuidades teóricas, ya sea del realismo, del idealismo o de algunas de sus derivaciones, el tema de los regionalismos puede ser categorizado en función de los siguientes arquetipos: como adaptación instrumental a las iniciativas de apertura de mercados, sobre todo de Estados Unidos; en tanto respuesta defensiva -estatal y regional- a las inflexiones pautadas por la globalización económica y un diseño estratégico unipolar; en tanto articulación de los actores que definen una cohesión cultural frente a otros entornos y que en su versión "civilizatoria" define una diversidad alrededor de la cual se estructuran los nuevos ejes de cooperación y conflicto en el sistema internacional; y en tanto "regionalismo abierto" teniendo como referencia la convergencia de políticas públicas y el consenso alrededor de determinados objetivos de política y desarrollo.

Estas cuatro versiones de interpretación de los regionalismos señalan la pertinencia del fenómeno en su faceta cualitativa de impacto en la definición de políticas tanto hacia el espacio regional, como en respuesta al entorno y a

\footnotetext{
${ }^{38}$ Un ejemplo de esta incertidumbre analítica en las consecuencias que puede aparejar para la seguridad regional las consecuencias de la globalización en las modalidades de funcionamiento de distintos actores (Estado, empresas y organizaciones internacionales), es presentado en el artículo de Antonio Ramalho da Rocha-Marcia Lissa Aida “Globalizaçào e regionalizaçào: dificuldades em sua análise”, en Revista Brasileira de Política Internacional año 38 nำ1 1, Instituto Brasileiro de Relaçòes Internacionais, Brasilia, 1995.

39 Algunos analistas parten de la base que con el "fin de la historia" comienza la época del "relato" ya sea en el sentido que se ha dado lugar a una nueva "Edad Media", ya sea desde una visión post-moderna de búsqueda de nuevas referencias. Véase al respecto, Luciano Tomassini, "La política internacional después del Muro" Estudios Internacionales nํㅜㅁ 91, Santiago de Chile, julio-setiembre 1990; Alain Ming, Un nouveau Moyen Age, Gallimard, Paris, 1993; Jean-François Revel, "Raison pure et raison pratique" Commentaire vol 12 , n1 48, Paris 1989-1990.
} 
la globalización. Si bien las versiones no convergen en sus puntos de partida $y$ en el marco explicativo que define el regionalismo en el escenario internacional, la vitalidad del fenómeno y sus consecuencias en el plano de la elaboración de las políticas, ameritan su inclusión en tanto actor diferenciado en las relaciones internacionales..$^{40}$

La consideración del regionalismo como actor diferenciado constituye una opción metodológica que posibilita el análisis de la respuesta estratégica del Estado y de la región, en distintos aspectos que hacen al cambio estructural que se está procesando. En ese sentido, las respuestas que se definan constituyen inflexiones desde los ordenamientos socio-políticos-sub-nacionales, nacionales y regionales- que van delineando las nuevas lógicas de interacción entre las comunidades humanas.

Lo que importa desde esta opción analítica son las manifestaciones que expresan en tanto "modelos" los tres procesos de integración regional considerados en lo que concierne la vinculación de la dimensión social con el comercio internacional. Desde ese punto de vista, resulta relevante la consideración del impacto de la política exterior de Estados Unidos en el proceso de integración de América del Norte en lo que concierne la relación de la dimensión social con la opción democrática y la liberalización del comercio; las respuestas que pueda otorgar la Unión Europea en tanto manifestación de un modelo cuya prioridad es la integración social; y las definiciones que se van planteando desde el MERCOSUR en tanto proceso específico, condicionado por la opción de inserción competitiva, lo cual se expresa en planteamientos sobre la liberalización del comercio y el libre acceso al mercado por una parte y las condiciones en que se definen los costos del producto entre los cuales se ubica el costo laboral, lo que se traduce en manifestaciones sobre el "dumping social".

La convergencia de una mayor presencia de la sociedad civil en Estados Unidos a través de diversas organizaciones en formación o en vías de consolidación (y no solamente de las organizaciones de trabajadores), cuya representatividad no resulta evidente y cuyos lazos con el sistema político no están definidos, con el interés de la política exterior de promover y ampliar los regímenes democráticos, posibilitó la firma de los Acuerdos Paralelos, entre los cuales el Acuerdo de Cooperación Laboral de América del Norte (ACLAN).

$4^{a}$ Esto lleva a diferenciar el regionalismo de un régimen internacional, cuyo marco explicativo se ubica en una interacciōn entre varios Estados, que aceptan una cooperación para disminuir los costos de transacciōn. 
El ACLAN define un paso histórico de relevancia al establecer un procedimiento para verificar incumplimientos de los Estados con la posibilidad de llegar a una sanción frente a la violación de determinados principios (seguridad e higiene en el trabajo, trabajo de menores y salarios mínimos), de los once enunciados como fundamentales en el Anexo I siempre que estén ligados con el comercio (art. 29 a) y se encuentren amparados por leyes laborales mutuamente reconocidas por los Estados (art. 29 b). ${ }^{41}$

ElALCAN ha sido cuestionado por las organizaciones sindicales y los juristas por considerar que se dejaban de lado varios principios en materia de supervisión sancionatoria; por la duración del procedimiento que puede llegar hasta a cuatro años antes de la sanción; y por condicionar la lógica implícita del Acuerdo a las legislaciones nacionales. ${ }^{42}$ Sin embargo, a pesar de estas críticas, de las pocas demandas presentadas y los efectos limitados de las mismas, ${ }^{43}$ es pertinente enfatizar que los efectos del Acuerdo en cuanto a los objetivos sociales deben buscarse a través del sistema de consultas y evaluaciones y en último término por el procedimiento de solución de controversias. En definitiva, los Estados se informan y consultan entre sí a través de las Oficinas Administrativas Nacionales o bien mediante solicitud por escrito a nivel ministerial de cualquiera de las Partes (arts. 21 y 22), y pueden llegar al nombramiento del Comité de Expertos en caso de que el asunto no se resuelva por las consultas ministeriales (art. 23).

En definitiva, si bien el Acuerdo Laboral resulta limitado en cuanto a la capacidad de supervisión y sanción del conjunto de principios laborales, constituye un precedente en el sentido de que los mismos pueden ser objeto de

\footnotetext{
${ }^{45}$ Los once principios laborales enunciados son: libertad de asociación y protección del derecho a organizarse; derecho a la negociación colectiva; derecho de huelga; prohibición del trabajo forzado; restricciones sobre el trabajo de menores; condiciones mínimas de trabajo; eliminación de la discriminación en el empleo; salario igual para hombres y mujeres; prevención de lesiones y enfermedades ocupacionales; indernnización en los casos de lesiones de trabajo o enfermedades ocupacionales; y protecciōn de los trabajadores migratorios.

42 En particular las críticas parten de organizaciones y juristas de Estados Unidos y Canadá. Así por ejemplo, los principios ligados a la libertad de asociación y a la negociación colectiva fueron excluidos de una supervisión que pudiera llevar a sanciones porque interferian con las legislaciones nacionales de México. Véase al respecto, René Laperrière, "Synthèse. Bilan, enjeux et perspectives: la commercialisation internationale des droits du travail", en René Laperrière (ed) Droits du travail et commece international, Yvon Blais, Université de Quêbec à Montréal, Dep. Sciences Juridiques, Canadá, 1995.

${ }^{43}$ De las nueve demandas recibidas por la Comisión vinculadas a las condiciones de trabajo en México, solamente seis fueron consideradas, las cuales llegaron a la instancia de la recomendación. Véase al respecto, Allef Benessaieh "De l'Amérique du Nord au projet hérnisphérique: les Etats-Unis, la clause sociale et l'art de la vertu démocratique" Etudes Internationales, vol. XXIX n² 4, Institut Québécois des Hautes Etudes Internationales, Université Laval, Canada, 1998.
} 
consultas y evaluaciones en un ámbito definido como lo es un proceso de libre comercio entre tres Estados, y además porque algunos principios pueden ser objeto de sanción siempre que tengan efectos en el comercio.

El eje de referencia para visualizar los avances registrados en materia laboral en el proceso de integración en América del Norte es la política exterior de Estados Unidos, en particular en tanto manifestación específica que se ha concretado en los noventa y que tiene como consecuencia plantear determinados parámetros de referencia en las relaciones laborales. De esta forma, el Acuerdo Laboral de América del Norte constituye un antecedente en tanto régimen específico cuya evolución en lo concerniente al vínculo entre normas laborales y comercio internacional dependerá de la conjunción de distintos factores: convergencia de principios en el plano intergubernamental, articulación del proceso con otros regímenes internacionales y en particular con el Acuerdo de Libre Comercio de las Américas y los avances que puedan surgir de la Ronda del Milenio, y las iniciativas que surjan de los actores de la sociedad civil, en la medida que son funcionales con la política exterior de Estados Unidos, en los distintos frentes en que se expresan y en especial en el Acuerdo de Libre Comercio de las Américas. ${ }^{44}$

En el caso del proceso de integración europeo el eje de referencia para analizar las consecuencias de la conexión de la dimensión social con el comercio internacional, es la política social definida en tanto «modelo» y las opciones que puedan manejarse por la puesta en marcha de la Unión Económica y Monetaria. La construcción de la política social en el proceso de integración europeo tiene sus fundamentos jurídicos en los artículos 136 a 150 del Tratado Constitutivo en su versión consolidada (anteriores artículos 117 a 128), que conforman el título XI (antiguo título VIII).45

El Tratado de Amsterdam aprobado en 1997, que ha entrado en vigor recientemente ( 1 de mayo de 1999), tiene algunas innovaciones de importancia que consolidan la idea de un modelo social específico en la integración europea que atañe a los distintos aspectos de la dimensión social y por lo tanto que incluye la producción, la distribución y el comercio. En primer lugar, la inclu-

\footnotetext{
44 El sentido estratégico de la integración en América del Norte y de su relación con el Acuerdo de Libre Comercio de las Américas es puntualizado en varios trabajos de Dorval Brunelle y Christian Deblock. Véase en particular, "De l'ALE à la ZLÉA: régionalisme et sécurité économiques dans les Amériques", Etudes Internationales XXVIII, $n^{0}$ 2, Québec, Canadá, 1997.

4s Estas modificaciones en el Tratado Constitutivo surgen de los cambios institucionales y normativos en el derecho originario que se procesaron en el Acta Única, Maastricht y finalmente en el Tratado de Amsterdam.
} 
sión en el Tratado Constitutivo de un Título dedicado al Empleo (Título VIII que corresponde a los artículos 125 a 130) y la inserción en el Tratado Constitutivo del Protocolo número 14 sobre la política social, que hasta el momento estaba anexado por la posición negativa del Reino Unido a su aprobación. Este peso de la dimensión social en una Conferencia Intergubernamental, señala la sensibilidad creciente del tema en la sociedad europea y la necesidad de las instituciones comunitarias y del sistema político europeo de encarar el mismo. ${ }^{46}$ En segundo lugar, la referencia explícita a la Carta Social de 1961 y a la Carta Comunitaria de los Derechos Sociales Fundamentales de los Trabajadores de 1989 (art. 136 del Tratado Constitutivo), lo cual otorga un sustento jurídico a la acción de la Corte de Justicia en materia social, en materia de derechos sociales fundamentales de los trabajadores ${ }^{47}$ En tercer orden, se mantiene la base de la decisión por unanimidad en ciertos dominios, pero el Tratado incorpora la obligatoriedad de la co-decisión, lo cual implica la intervención comunitaria del Parlamento Europeo y no solamente la consulta del mismo para esos temas, como sí continúa siendo el caso para el Comité Económico y Social y el Comité de las Regiones. ${ }^{48}$ Por otra parte, el Tratado prevé el fomento de la colaboración entre los Estados miembros y además faci-

\footnotetext{
${ }^{46}$ Diversos pronunciamientos y análisis impulsan esta marcha de la dimensión social en la integración europea en los últimos años. En lo que concierne al empleo, los diferentes documentos de la Comisión, entre los cuales el Libro Verde antecedente de reflexión y análisis del Libro Blanco "Crecimiento, competitividad y empleo" y el nuevo libro verde que data de 1997 referido a los criterios para una nueva organización del trabajo, señalan una reflexión acentuada sobre el empleo y las perspectivas de una nueva organización de la sociedad que incluya los diferentes recursos humanos y sociales y por otra parte disminuya determinados costos y pérdidas sociales. Estos documentos tuvieron su efecto en la inclusiôn de un título sobre el empleo en el Tratado Constitutivo y en la realización de una Cumbre sobre el Empleo en Luxemburgo en noviembre de 1997 , en donde se adoptaron determinadas líneas directrices para las políticas de empleo. En lo que se refiere a los principios sociales, la Carta Comunitaria de los derechos sociales fundamentales de los trabajadores, aprobada en 1989, la inclusión en el Tratado de Maastricht de un vínculo obligatorio entre la adopción de directivas en materia social por parte del Consejo y los asociados en el diảlogo social; y la adopciôn del Protocolo número 14 como fuente comunitaria al incluir los principios sociales como parte del Tratado Constitutivo, son elementos que afirman la intención de apoyar la especificidad del modelo europeo. Además de estas dos líneas en materia de política social y empleo, diversas directivas adoptadas sobre todo en los ültimos años, muestran el interés derivado de no discriminar, de los derechos colectivos y de las condiciones de trabajo. Véase al respecto, Anne Meyer, L'Europe Sociale, La Documentation Française, Problèmes Politiques et Sociaux no 797, París 1998; Annick Mallet - Marie-Cécile Milliat, Introduction à L'Europe Sociale, Editions de l'Ecole Nationale de la Santé Publique, Col. Politiques et Interventions Sociales, Francia, 1997.

${ }_{47}$ En ese sentido el cierre de la empresa Renault en Vilvorde muestra las dificultades de pasar del cuadro nacional al regional en materia de políticas sociales, debido a las insuficiencias de la normativa regional en ese dominio. Sin embargo, el hecho de que la empresa fuera condenada por no respetar las obligaciones y además que el tema ocasionara movimientos y debates regionales y no solamente locales o nacionales, da muestra de la existencia de una conciencia regional sobre el tema. Sobre los aspectos jurídicos y de procedimiento del conflicto, véase Marie-Ange Moreau "A propos de l'affaire Renault", Droit Social núm. 5, Paris, 1997.
} 
litar la coordinación de las acciones en todos el ámbito de la política social que se incluye.

La referencia al "modelo" europeo en su dimensión social debe completarse con la obligatoriedad de la Comisión de consultar a los interlocutores sociales antes de presentar propuestas comunitarias en el ámbito de la política social y el cometido de la Comisión de fomentar la consulta a los interlocutores sociales en el nivel comunitario y adoptar todas las disposiciones necesarias para facilitar su diálogo, velando por que ambas partes reciban un apoyo equilibrado (art. 138).

Si bien las diferencias en materia del costo laboral han sido asimiladas en el proceso de integración europea, por la consideración de otros factores que hacen a la competitividad, los riesgos de "dumping social"y de que se produzca un efecto regresivo en cascada se encuentran presentes, debido en particular a la puesta en marcha de la unión económica y monetaria, ya que la variable laboral puede pasar a ser el mecanismo de ajuste. ${ }^{49}$

La confirmación de determinados principios en materia de política social y la inclusión comunitaria de un título sobre el empleo y de determinados principios sociales, se encuentra por lo tanto acotada por las posibles derivaciones de la puesta en marcha de la unión económica y monetaria. Además de ello, la agenda europea en materia de ampliación hacia los países de Europa Central y Oriental plantea de por sí nuevas tensiones en materia de la aplicación y supervisión de principios sociales básicos y la tentación de apostar a la disminución de determinados parámetros en las condiciones laborales con las consecuencias en materia de "dumping social". Finalmente, la proximidad de la Ronda del Milenio expone a la Unión Europea con el desafío de plantear el modelo europeo como una alternativa posible, tanto hacia Europa, como hacia otros países y procesos regionales.

Al tomar solamente estos dos procesos, la posible convergencia de objetivos y de instrumentos en materia de conexión de la dimensión social con el comercio internacional, podría ser significativa de cara a la Ronda del Milenio,

\footnotetext{
$4^{8}$ Se trata del ámbito de la salud y seguridad de los trabajadores, las condiciones de trabajo, la informa. ción y consulta a los trabajadores, la integración de las personas excluidas del mercado laboral, y la igualdad de hombres y mujeres en lo que respecta a oportunidades en el mercado laboral y el trato en el trabajo (art. 137 del Tratado Consolidado).

49 Philippe Pochet -Bart Vanhercke (ed), Les enjeux sociaux de l'Union Économique et Monétaire, Presses Interuniversitaires Européennes- Observatoire Social Européen, Bruselas, 1998. En lo que concierne la relación entre el nivel nacional y el regional, vẻase Fabrice Fries, Les grands dëbats européens, Edd du Seuil, París, 1995.
} 
sobre todo teniendo en cuenta la envergadura política y comercial de los dos bloques. Ahora bien, no es nada evidente de que pueda llegarse a una convergencia debido a los distintos ejes de referencia señalados, al hecho de que se está delante de dos modelos regionales diferentes, a los instrumentos que se expresan en cada proceso y a los actores implicados.

En cuanto a los objetivos, es bastante evidente que una zona de libre comercio tiene un alcance específico en cuanto a su repercusión en las políticas públicas y sociales de lo que surge de un mercado común, que está procesando el pasaje a la unión económica y monetaria. Si se toma en particular el tema de la dimensión social, en el caso de la integración en América del Norte, es necesario remitirse a las opciones de política exterior de Estados Unidos, debido a que las iniciativas en términos del orden mundial solamente pueden surgir de ese país en las Américas. Es en ese sentido que debe incluirse en la respuesta a esta interrogante los avances que ha tenido la política exterior de Estados Unidos en lo que concierne la dimensión social en el Acuerdo de Libre Comercio de las Américas.

En esa dirección, la posición de Estados Unidos sobre los actores de la sociedad civil, los instrumentos para la participación de los mismos y la vinculación de las relaciones laborales con la producción y el comercio, presenta las siguientes características: busca garantizar el compromiso y el apoyo del público al proceso de liberalización económica hemisférica y la participación de los individuos y organizaciones para respaldar la democracia, sin que sea evidente la relación entre la "sociedad civil", el sistema político y las organizaciones sociales existentes; plantea la vinculación de las relaciones laborales en su conjunto (normas internacionales, condiciones laborales, higiene y seguridad, entre otros) con el comercio, con la finalidad de liderar la transición del régimen de comercio internacional y posibilitar un mercado más transparente, ordenado y estable; y utiliza para ello como foro de negociación, supervisión y difusión acuerdos abiertos en que se negocia permanentemente.

En el proceso de integración europeo, el punto de partida es el debate sobre la construcción de un modelo social y los ejes actuales del mismo tienen relación con la evolución del regionalismo europeo y la posibilidad de definir alternativas a la interdependencia global. Por otra parte, la construcción del modelo social europeo está referido a la integración europea, tanto en lo que concierne el modelo político -institucional de funcionamiento, como en lo que se refiere al marco en el cual se ubican (e identifican) los actores políticos 
y sociales. Además de ello, el Tratado Constitutivo en tanto fuente jurídica va consolidando la idea de la construcción del modelo social, como se indicara anteriormente. El Tratado Constitutivo incluye además al Parlamento Europeo, cuyos integrantes han sido elegidos por la ciudadanía europea, en la codecisión en ámbitos de la política social y a los interlocutores sociales, cuyos ámbitos de referencia nacional y regional se encuentran legitimados, en las instancias de consulta sobre la política social comunitaria.

Las diferencias existentes entre ambos modelos hace imposible pensar en un acuerdo instrumental o de objetivos en cuanto a la vinculación de la dimensión social con el comercio en el espacio del Atlántico Norte. Sin embargo, las tensiones derivadas de las condiciones externas y su reflejo en la Ronda del Milenio pueden derivar en iniciativas más agresivas de parte de Estados Unidos en este ámbito y un acomodamiento cooperativo contra otras regiones. A su vez, la situación interna del espacio europeo puede llevar a que se disuelvan los avances en la política social, debido a la necesidad de hacer adaptaciones para el funcionamiento de la unión económica y monetaria.

El caso del proceso de integración del MERCOSUR en cambio se encuentra limitado por la necesidad de insertar las economías en el mercado mundial y los costos que representa el "dumping social". La respuesta regional al tema de la internacionalización del mercado laboral y su vinculación con el comercio ha sido expresada recientemente por el MERCOSUR a través de la Declaración Socio-Laboral del MERCOSUR aprobada en diciembre del año $1998 .^{50}$ En la Declaración, se señala explícitamente que ésta no podrá invocarse ni utilizarse para otros fines que no estén en ellos previstos, y en particular, su aplicación a cuestiones comerciales, económicas y financieras (art. 25 de la Declaración). La Declaración define los principios y derechos en el área del trabajo, tanto individuales (no-discriminación, promoción de la igualdad, derecho de los trabajadores migrantes y fronterizos, eliminación del trabajo forzoso, trabajo infantil y de menores, derecho de los empleadores) y derechos colectivos (libertad de asociación, libertad sindical, negociación colectiva, huelga, diálogo social) y define otros derechos entre los cuales el fomento del empleo, la protección de los desempleados, la formación profesional y el desarrollo de recursos humanos, la salud y seguridad en el trabajo y la se-

so Como antecedente de la evolución de la cuestión laboral en el MERCOSUR puede consultarse a Guillermo Campero, La cuestión laboral en el MERCOSUR: procesos, opciones y posibilidades, PROSUR, Friedrich Ebert Stiftung, Santiago de Chile, 1999. 
guridad social. ${ }^{51}$ Para respetar los derechos señalados y promover su aplicación, la Declaración recomienda instituir una Comisión Socio-Laboral, en tanto órgano tripartito auxiliar del Grupo Mercado Común, que tendrá carácter promocional, dotado de instancias nacionales y regional (artículo 20). La lógica tripartita adoptada para la Comisión de seguimiento otorga continuidad a la metodología adoptada en el Sub-Grupo de Trabajo "Relaciones Laborales, empleo y seguridad social" del Grupo Mercado Común del MERCOSUR, única instancia en que se plantea esa composición con el objetivo de promover y supervisar el conjunto de derechos relacionados con el trabajo, a los cuales se han adjuntado los derechos vinculados al desempleo en sentido general (derechos específicos de los desempleados, además del derecho al empleo y otros).

El "modelo" del MERCOSUR mantiene por el momento la separación entre la dimensión laboral y el comercio, manteniendo la lógica tripartita en la supervisión de las condiciones de trabajo, pero ampliando la nómina de principios y derechos a ser aplicables en el plano regional y nacional. Por otra parte, la sociedad civil puede expresarse a través del Foro Consultivo Económico y Social, y su ámbito de referencia se remite a todo tema de importancia social. El Foro tiene instancias nacionales donde se plantean los asuntos de interés específico y una instancia regional donde se debaten los temas que surgen de la agenda regional. El Foro ha articulado una estrategia de interacción con la Comisión Parlamentaria Conjunta, que hasta el momento ha servido para información, debate y apertura de temas institucionales.

El "modelo" MERCOSUR no está aislado de los otros "modelos" que se manifiestan en instancias de negociación diversas. Por una parte, el MERCOSUR participa del Acuerdo de Libre Comercio de las Américas, en donde Estados Unidos ha planteado las iniciativas del grupo de seguimiento sobre trabajo y comercio y sobre la conformación de la sociedad civil. Por otra parte, el MERCOSUR ha iniciado una negociación con la Unión Europea para conformar una zona de libre comercio, y además mantiene un diálogo político bilateral.

La interacción del MERCOSUR con Estados Unidos en el marco del Acuerdo de Libre Comercio de las Américas y con la Unión Europea, posibi-

\footnotetext{
\$2 La Declaración Sociolaboral tiene cuatro partes; "derechos individuales", que comprende los artículos 1 a 7; "derechos colectivos", que incluye los artículos 8 a 13; "otros derechos", que va del articulo 14 al 19; y finalmente "aplicación y seguimiento" que comprende los artículos 20 al 25.
} 
lita visualizar un escenario tripartito occidental, cuyos pasos futuros serán significativos a los efectos de la conformación de esta región-mundo. En ese sentido, en lo que concierne la dimensión social, la identidad de tres modelos resulta visible tanto en lo que concierne a los objetivos de los distintos procesos, como en los instrumentos definidos, pero sobre todo en los actores implicados, su participación y en la legitimidad de los mismos.

\section{Conclusiones}

El objetivo de este trabajo ha sido visualizar los avances y respuestas que otorgan los procesos regionales de América del Norte, de Europa y del Cono Sur de América Latina frente a la inclusión de la dimensión social en el comercio internacional. Este objetivo abre un conjunto de temas complejos relacionados con el papel de los organismos internacionales frente a la posibilidad de regular el vínculo entre el «costo laboral» y el comercio internacional, las definiciones de la política exterior de Estados Unidos para ordenar el régimen de comercio internacional, la introducción de la sociedad civil y sus consecuencias en el control de los principios sociales y la viabilidad de los regionalismos en definir respuestas diferenciadas en tanto «modelos» sociales frente a la interdependencia global.

El estudio parte de un conjunto de consideraciones sobre las modificaciones que se están procesando en las condiciones en que se estructuran las pautas de convivencia de las comunidades humanas en sus diferentes planos. Estas modificaciones estructurales condicionan las diferentes respuestas estratégicas de los distintos entornos en que se organizan las comunidades humanas: en lo local, sub-nacional, nacional, sub-regional, continental e internacional. Por otra parte, estas modificaciones estructurales están condicionando también las percepciones sobre los principios y valores básicos, configurando otro canal de cooperación/discordia a través de las identidades culturales. Estas consideraciones ayudan a comprender, en buena medida, las dificultades encontradas para poder considerar los costos globales de un producto que se incorpora al mercado internacional.

Distintos estudios realizados enfatizan que la internacionalización del mercado laboral no depara de por sí una aproximación de los Estados. En ese sentido, las diferentes respuestas que se plantean desde las respectivas tradicio- 
nes culturales afectan a la organización productiva, las condiciones y generación de empleo, la distribución del mercado de productos, la evolución de la sociedad civil y el régimen de comercio internacional. Este vacío en el régimen internacional ha sido en parte sostenido por las dificultades que han manifestado los organismos internacionales para avanzar en el marco multilateral. Como los cambios de régimen internacional pueden provenir en particular de las iniciativas y avances del poder hegemónico, se planteó la evolución de la política exterior de Estados Unidos en ese tema, y se enfatizaron los equilibrios socio-políticos de la política doméstica y los avances en la Ronda del GATT, en la aprobación del Acuerdo de Cooperación Laboral de América del Norte (uno de los acuerdos paralelos del Tratado de Libre Comercio de América del Norte) y en el Acuerdo de Libre Comercio de las Américas. Estos avances en la "dimensión social" de la política exterior de Estados Unidos coinciden con demandas provenientes de parte de la sociedad civil estadounidense, lo cual provoca un efecto de alimentación mutuo.

En otro escalón del análisis se estudió la pertinencia analítica de los nuevos regionalismos en tanto variables intermedias entre las respuestas diferenciadas de los Estados y las perspectivas de una armonización planteada desde el sistema internacional, vía potencia hegemónica. En ese sentido, el análisis de la integración en América del Norte, en Europa y en el Cono Sur de América Latina, nos enfrenta a tres procesos que se diferencian por los objetivos, los instrumentos utilizados y los "modelos" sociales, lo cual repercute necesariamente en la definición del tema de la vinculación de las relaciones laborales con el comercio. Lo que se plantea en este estudio es que esas diferencias dificultarán la conformación de un espacio transatlántico occidental, tal como ha sido planteado por algunos trabajos. Por otra parte, estas diferencias provocarán la necesidad de otras definiciones en el MERCOSUR, por el hecho de que participa del Acuerdo de Libre Comercio de las Américas y mantiene el objetivo de definir una zona de libre comercio con la Unión Europea. 